\title{
Analysis of damage in commercial natural rubber through NMR spectroscopy
}

Nghiem Thi Thuong, ${ }^{\mathrm{a}, \mathrm{b}}$, Yoshimasa Yamamoto ${ }^{\mathrm{c}}$, Phan Trung Nghia ${ }^{\mathrm{d}}$ and Seiichi Kawahara $^{\mathrm{a}}$ *

${ }^{a}$ Department of Materials Science and Technology, Faculty of Engineering, Nagaoka University of Technology, 1603-1, Kamitomioka-machi, Nagaoka, Niigata 940-2188, Japan.

${ }^{b}$ Department of Physical Chemistry, School of Chemical Engineering, Hanoi University of Science and Technology, No.1, Dai Co Viet Street, Hai Ba Trung District, Hanoi, Vietnam.

${ }^{c}$ Department of Materials Science and Technology, Tokyo National College of Technology, 1220-2 Kunugida-machi, Hachioji, Tokyo 193-0997, Japan

${ }^{\mathrm{d}}$ Department of Inorganic Chemistry, School of Chemical Engineering, Hanoi University of Science and Technology, No.1, Dai Co Viet Street, Hai Ba Trung District, Hanoi, Vietnam.

*Corresponding author. Tel.: +81 25847 9301; fax: +81 25847 9300. E-mail address: kawahara@mst.nagaokaut.ac.jp (S. Kawahara) 


\section{ABSTRACT}

Damage to natural rubber (NR) during processing was investigated through liquid state NMR spectroscopy. Various commercial rubbers were used in the present study such as Pale Crepe (PC), Rubber Smoked Sheet (RSS3), Technically Specific Sheet $\left(\mathrm{TSS}^{\circledR}{ }^{\circledR}\right.$ ), Standard Thai Rubber (STR5L), and Standard Malaysian Rubber (SMR20). As-cast films of the rubbers were prepared by solution casting method and followed by purification by acetone extraction. Chemical structures of the rubbers were elucidated through ${ }^{1} \mathrm{H},{ }^{13} \mathrm{C}-\mathrm{NMR}$, and DEPT spectroscopy. The ${ }^{13} \mathrm{C}-\mathrm{NMR}$ signals at 39.8 and $40.0 \mathrm{ppm}$ were assigned to the trans-1,4-isoprene unit in the trans-trans and cis-trans sequences, respectively, while the signals at 60.8 and $64.5 \mathrm{ppm}$ were assigned to $\mathrm{C} 2$ and $\mathrm{C} 3$ of an cis epoxy group. The cis epoxy groups were identified for PC, STR5L, RSS3, TSS8 ${ }^{\circledR}$, and SMR20, whereas the trans-1,4-isoprene units from cis-trans isomerization were detected for TSS $8^{\circledR}$ and SMR20. The amount of these groups in TSS8 ${ }^{\circledR}$ and SMR20 were higher than those in PC, STR5L, and RSS3. Mechanical properties of TSS $8^{\circledR}$ and SMR20 were found to be inferior to those of PC, STR5L and RSS3. The mechanical properties depended mainly upon the damage of the samples during processing.

Keywords: commercial natural rubber, NMR, processing, isomerization, epoxidation 


\section{Introduction}

Abnormal groups of natural rubber (NR), which form gel fraction as a crosslinking junction, prevent analysis of their structure, since the gel fraction is insoluble in deuterated solvents. The abnormal groups, i.e. epoxy groups, trans-1,4-isoprene units, formyl groups, cyclic ester groups (lactone) and so forth, are known to react to each other to crosslink NR molecules [1,2]. In addition, the long sequence length of the cis1,4-isoprene units may be reduced, when the abnormal groups were added onto the backbone of the rubber molecules. The decrease in the long sequence length of the cis-1,4-isoprene units may suppress crystallization of NR on stretching, i.e. straininduced crystallization. For instance, the presence of trans-1,4-isoprene units due to isomerization on the main-chain of the rubber molecules significantly decreases crystallization of NR upon stretching [3]. The suppressed crystallization on stretching may deteriorate the excellent mechanical properties of NR such as tensile strength, tear strength, permanent set and so forth. Therefore, it is necessary to decrease the amount of the abnormal groups of NR to maintain the long sequence length of cis-1,4isoprene units which are responsible for the outstanding mechanical properties of NR. The abnormal groups of NR may be characterized by NMR spectroscopy after converting insoluble gel fraction to soluble fraction through two methods, i.e. physical and chemical methods, since physical and chemical crosslinking junctions are formed with the abnormal groups. The abnormal groups may be isolated after decomposition of the crosslinking junctions. One of the plausible methods to decompose the chemical crosslinking junctions is transesterification with $\mathrm{CH}_{3} \mathrm{ONa}$ [4], whereas that to decompose the physical crosslinking junctions is addition of polar solvents [5]. Transesterification is useful for decomposition of ester linkages while the other chemical linkages formed with the abnormal groups still remain 
undecomposed. In contrast, all physical crosslinking junctions are decomposed by strong polar solvents, which convert gel fraction to branched molecules. Therefore, in the present work, we use the strong polar solvents to develop a new method to analyze the structure of abnormal groups of NR.

In previous works [6,7], analysis of abnormal groups of commercial NR through NMR spectroscopy has been done with sol fraction, which was separated from the gel fraction through filtration. For instance, Farley carried out ${ }^{1} \mathrm{H}-\mathrm{NMR}$ measurements for the sol fraction obtained from several commercial rubbers and found that the trans1,4-isoprene unit content varied between rubber grades, suggesting that cis-trans isomerization of NR may be an additional source of the trans-1,4-isoprene unit [7]. However, cis-trans isomerization was not confirmed in this case due to lack of the signal corresponding to cis-trans isomerization in the ${ }^{13} \mathrm{C}-\mathrm{NMR}$ spectrum. On the other hand, Eng and co-workers reported that the signal from cis-trans isomerization was detected for UV-degraded and masticated NR through ${ }^{13} \mathrm{C}$-NMR spectroscopy [8]. In addition, we performed ${ }^{1} \mathrm{H}-\mathrm{NMR}$ measurements for commercial rubbers, and found that, in certain cases, commercial rubbers undergo epoxidation [9]. However, whether cis-trans isomerization and epoxidation occur during NR processing remains ambiguous.

Epoxidation and cis-trans isomerization may be associated with the procedure to manufacture commercial NR [9,10]. Generally, manufacture of commercial NR involves many steps, including (1) coagulating field latex, (2) washing with water, (3) milling and sheeting, (4) drying, and (5) storing in a warehouse [11]. Among these, the drying step may result in the oxidative degradation, which introduces several abnormal groups on the rubber chain. This assumption is based on the fact that the structure of the long sequence of the cis-1,4-isoprene units in NR is very sensitive to 
the thermal condition (i.e. high-temperature processing). Therefore, it is important to characterize the structure of commercial NR and to investigate the effect of the processing conditions on the abnormal groups in commercial NR.

In the present work, the appearance of abnormal groups in commercial NR and the effect on the mechanical properties were investigated. First, we characterized the commercial NR through liquid state NMR spectroscopy. Then, the effect of processing condition on the chemical structure of the rubbers was discussed with respect to the appearance of several abnormal groups. In addition, tensile strength was measured to examine the effect of oxidative degradation during processing of the rubbers.

\section{Experimental}

\subsection{Materials}

The commercial NR used in the present study were Standard Thailand Rubber (STR5L), Ribbed Smoked Sheet (RSS3), Technically Specified Sheet (TSS $8^{\circledR}$ ), Pale Crepe (PC), and Standard Malaysian Rubber (SMR20). SMR20, STR5L, RSS3, PC are commercially available as a bulk and $\operatorname{TSS} 8^{\circledR}$ is prepared from an unsmoked sheet of NR by Von Bundit Co. Ltd, Thailand. To elucidate the influence of the drying temperature during processing, these samples were selected based on the different drying temperatures during processing. PC is usually dried for $2-4$ days at $35-40$ ${ }^{\circ} \mathrm{C}$ whereas RSS3 is dried in a smokehouse for about one week at $60-70{ }^{\circ} \mathrm{C}$. Lower grade rubber (i.e. SMR20) is dried at a very high temperature (i.e., > $\left.100{ }^{\circ} \mathrm{C}\right)$ [11]. All other reagents were commercial grade.

\subsection{Preparation of the rubber films}

The rubber films were prepared by the solution casting method (Fig. 1). First, a commercial solid rubber was dissolved in dried toluene (1-2 w/w\%) while stirring for 
24 hours. Then a small amount of methanol $(2-4 \mathrm{w} / \mathrm{w} \%$ of the total weight of toluene solution) was added to dissolve the soft gel. The resulting solution was cast onto a petri dish and dried in a vacuum at room temperature to obtain a rubber film. The film was subsequently purified with hot acetone for 24 hours and dried in a vacuum at 30 ${ }^{\circ} \mathrm{C}$ for 3 days before characterization.

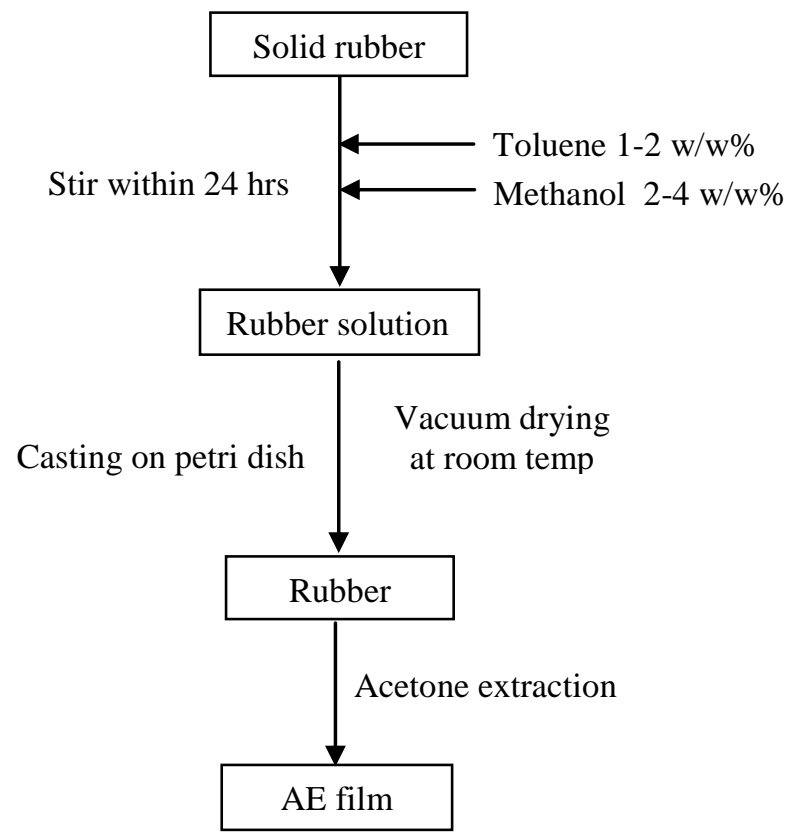

Fig.1. Preparation of a rubber film by the solution casting method

\subsection{Transesterification}

Transesterification of the acetone-extracted commercial rubbers was carried out in a toluene solution $(1 \mathrm{w} / \mathrm{w} \%)$ by a reaction with freshly prepared sodium methoxide while stirring at room temperature under a $\mathrm{N}_{2}$ atmosphere for 3 hours. The resulting transesterified rubber was purified by precipitating the rubber solution using an excess (three times) methanol and dried in a vacuum at room temperature for a week.

\subsection{Fourier transform infrared spectroscopy (FT-IR) analysis}

The amount of fatty acid ester groups was determined based on the calibration curve prepared using a mixture of stearic acid methyl ester and synthetic cis-1,4polyisoprene, Kuraprene IR10. FT-IR measurement samples were prepared by casting 
a chloroform solution ( $2 \mathrm{w} / \mathrm{w} \%)$ onto a $\mathrm{KBr}$ disk. The FT-IR experiments were performed by a JASCO FT-IR 410 spectrometer at 100 scans ranging from 400 to $4000 \mathrm{~cm}^{-1}$ with a resolution of $4 \mathrm{~cm}^{-1}$.

\subsection{Size exclusion chromatography (SEC) measurements}

The molecular weight and the molecular weight distribution of the rubbers were measured with a LC-2000 GPC, consisting of a PU-2080 JASCO pump, RI-2031 differential refractometer, and a UV-8011 UV detector. Each measurement was conducted at $30^{\circ} \mathrm{C}$ with a THF flow rate of $1 \mathrm{ml} / \mathrm{min}$. The rubber solution was prepared by the dissolution of rubber into tetrahydrofuran $(0.05 \mathrm{w} / \mathrm{v} \%)$ and filtered through a $0.1-\mu \mathrm{m}$-thick membrane filter $\left(\right.$ Whatman $\left.^{\circledR}\right)$. Standard polystyrene (TOSOH) was used to calibrate the molecular weight.

\subsection{Nitrogen content determination (Kjeldahl method)}

The nitrogen content of the commercial rubber films was determined by Kjeldahl method as described in Rubber Research Institute of Malaysia Test Method B7 [12]. A mixture of rubber $(0.1 \mathrm{~g})$ and a catalyst $(0.65 \mathrm{~g})$ with a ratio of 15:2:1 ( $\left.\mathrm{K}_{2} \mathrm{SO}_{4}: \mathrm{CuSO}_{4}: \mathrm{Se}\right)$ was digested with concentrated $\mathrm{H}_{2} \mathrm{SO}_{4}(2.5 \mathrm{ml})$ until the digested solution turned clear green. The resulting solution was distilled, and the distillate was titrated with $\mathrm{H}_{2} \mathrm{SO}_{4}(0.01 \mathrm{~N})$ with methyl red as an indicator. The end point of the titration was determined when the color changed from yellow to light pink. A blank sample without rubber was prepared using a similar method. The equation to determine the nitrogen content is given as

$$
\% \mathrm{~N}=\frac{\left(\mathrm{V}_{1}-\mathrm{V}_{0}\right) \times 10^{-3} \times 0.01 \times 14}{0.1} \times 100
$$

where $\mathrm{V}_{1}$ and $\mathrm{V}_{0}$ are the volume (ml) of $\mathrm{H}_{2} \mathrm{SO}_{4}$ for titration of the sample and blank sample, respectively. 


\subsection{Nuclear magnetic resonance (NMR) spectroscopy}

Liquid state NMR measurements were performed with a JEOL ECA-400 FT-NMR spectrometer (JEOL, Tokyo, Japan) operating at 400 and $100 \mathrm{MHz}$ for ${ }^{1} \mathrm{H}$ and ${ }^{13} \mathrm{C}$, respectively. The ${ }^{1} \mathrm{H}$-NMR measurements were performed in a 5 -mm $\phi$ tube with $\mathrm{C}_{6} \mathrm{D}_{6}$ as a solvent at $50^{\circ} \mathrm{C}$ for 5000 scans at the pulse repetition time of $7 \mathrm{~s}$ with recycle delay of $4.24 \mathrm{~s}$. The ${ }^{13} \mathrm{C}-\mathrm{NMR}$ and DEPT measurements were performed in a $10-\mathrm{mm} \phi$ tube in $\mathrm{CDCl}_{3}$ at room temperature in a JEOL EX-400 for 40000 scans at the pulse repetition time of $5 \mathrm{~s}$ with recycle delay of $3.79 \mathrm{~s}$.

\subsection{Tensile measurements}

Tensile tests were conducted at room temperature using a TOYOSEIKI universal tester VG10E according to JIS K6251. Dumbbell-shaped rubbers No.7 ( 1-mm thick) were subjected to the tensile test. The crosshead speed was $200 \mathrm{~mm} / \mathrm{min}$. The measurement was repeated three times for each sample.

\section{Results and discussion}

Fig. 2 shows the ${ }^{1} \mathrm{H}-\mathrm{NMR}$ spectra for acetone-extracted PC, RSS3, STR5L, TSS $8^{\circledR}$, and SMR20. Three major signals appeared at 1.77, 2.20 and $5.29 \mathrm{ppm}$, which were assigned to the methyl $\left(\mathrm{CH}_{3}\right)$, methylene $\left(\mathrm{CH}_{2}\right)$, and methine proton $(\mathrm{CH})$ of the cis1,4-isoprene unit. In addition, several small signals appearing in ${ }^{1} \mathrm{H}-\mathrm{NMR}$ spectra of the samples may be attributed to the signals of the abnormal groups or the non-rubber components present in NR. For instance, the signals at 3.92, 4.03, 4.08, and $4.22 \mathrm{ppm}$ were assigned to the methylene proton linking the mono- and diphosphate groups of the phospholipid at the $\alpha$-terminal unit as reported in the literature [13]. The signals at 2.80 and 5.63 ppm were likely due to the methylene proton $\left(-\underline{\mathrm{H}}_{2}-\mathrm{CH}=\mathrm{CH}-\right)$ and methine proton $\left(-\mathrm{CH}_{2}-\mathrm{C} \underline{\boldsymbol{H}}=\mathrm{C} \underline{\boldsymbol{H}}-\right)$ of the unsaturated fatty acids (e.g, linoleic or linolenic acid), which link to the NR molecules. These signals were also observed in 
the ${ }^{1} \mathrm{H}-\mathrm{NMR}$ spectrum for the rubber purified from commercial high-ammonia latex, which may possess the characteristic for the rubber before undergoing processing.

The signal at $2.63 \mathrm{ppm}$ was assigned to the methine proton of an epoxidized isoprene unit. As previously reported, this signal could be attributed to the oxidative degradation of NR and unsaturated fatty acids [9]. In the present work, the appearance of the signal in the ${ }^{1} \mathrm{H}-\mathrm{NMR}$ spectra of the samples after acetone extraction confirmed that the epoxy group was mainly present on the backbone of NR and was not a side group or associated with non-rubber impurities. This signal provides direct evidence that epoxidation occurs in commercial rubbers.

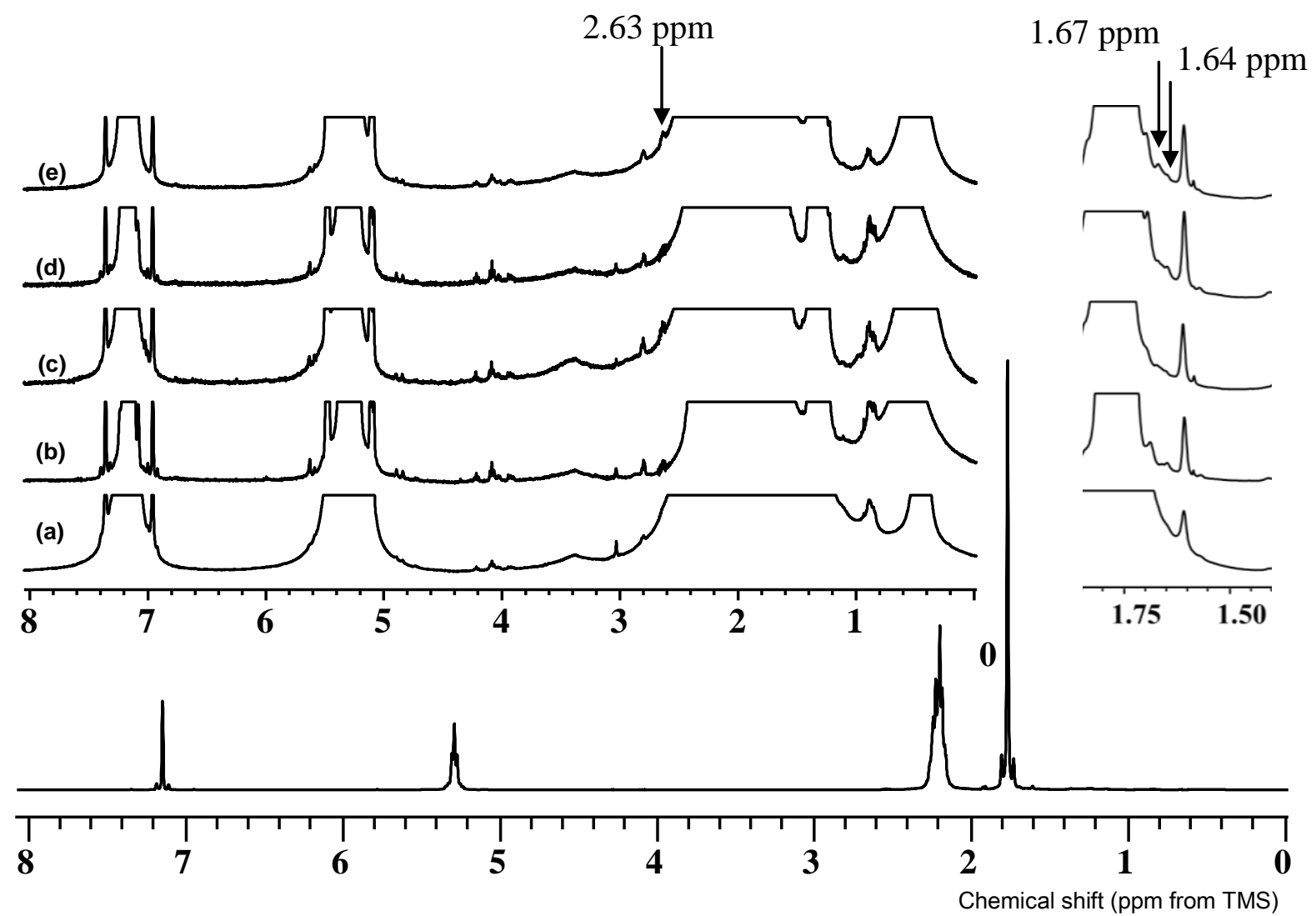

Fig. 2. ${ }^{1}$ H-NMR spectra for (a) PC-AE, (b) RSS3-AE, (c) STR5L-AE, (d) TSS8 ${ }^{\circledR}$-AE and (e) SMR20-AE 
In the methyl proton region, which ranges from 1.5 to $1.8 \mathrm{ppm}$ (cf Fig. 2), one signal at $1.64 \mathrm{ppm}$ was found for PC, RSS3, and STR5L, whereas two signals at 1.64 and $1.67 \mathrm{ppm}$ were found for $\operatorname{TSS}^{\circledR}$ and SMR20. In the literature, the signal at $1.64 \mathrm{ppm}$ was assigned to the methyl proton of the trans-1,4-isoprene unit in the trans-trans sequence and that at $1.67 \mathrm{ppm}$ was assigned to the methyl protons of the trans-1,4isoprene unit in the cis-trans sequence $[8,13]$. These two signals were not observed clearly in the ${ }^{1} \mathrm{H}-\mathrm{NMR}$ spectra for the commercial rubbers.

The rubbers were subjected to transesterification because transesterification has been known to decompose the branching points associated with the linked fatty acid, yielding a linear chain. In Fig. 3, which shows the ${ }^{1} \mathrm{H}-\mathrm{NMR}$ spectra for sol fraction of transesterified commercial NR between 1.4 and $1.8 \mathrm{ppm}$, the signals at 1.64 and 1.67 were clearly resolved. Consistent with the above assignment, the signal at $1.67 \mathrm{ppm}$ was observed in ${ }^{1} \mathrm{H}-\mathrm{NMR}$ spectra of $\operatorname{TSS} 8^{\circledR}$ and SMR20. These results suggest that cis-trans isomerization occurs in $\mathrm{TSS}^{\circledR}{ }^{\circledR}$ and SMR20, but not in PC, STR5L, and RSS3. 


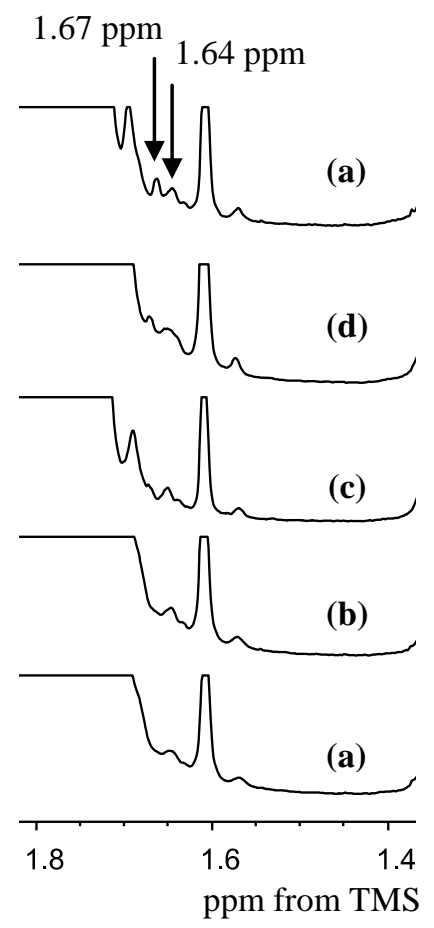

Fig.3. Expanded ${ }^{1} \mathrm{H}-\mathrm{NMR}$ spectra for sol fraction of (a) PC-TE, (b) RSS3-TE, (c) STR5L-TE, (d) TSS $8{ }^{\circledR}-$ TE and (e) SMR20-TE

To confirm the assignment for ${ }^{1} \mathrm{H}$-signals, we performed ${ }^{13} \mathrm{C}$-NMR measurements for these samples in $\mathrm{CDCl}_{3}$ (Fig. 4). The five characteristic signals for the cis-1,4isoprene unit in NR appeared at 23.4, 26.4, 32.2, 125.0, and $135.2 \mathrm{ppm}$, which were assigned to $\mathrm{C} 5, \mathrm{C} 4, \mathrm{C} 1, \mathrm{C} 3$ and $\mathrm{C} 2$ of cis-1,4-isoprene, respectively. One signal at 39.8 ppm appeared in the ${ }^{13} \mathrm{C}-\mathrm{NMR}$ spectra of PC, RSS3, and STR5L, whereas two signals at 39.8 and $40.0 \mathrm{ppm}$ were found in the ${ }^{13} \mathrm{C}-\mathrm{NMR}$ spectra of $\mathrm{TSS} 8^{\circledR}$ and SMR20. The previous literature attributed the signals at 39.8 and $40.0 \mathrm{ppm}$ to the methylene carbon of the trans-1,4-isoprene units in the trans-trans and the cis-trans sequences, respectively [8]. The trans-trans sequence may originate from the $\omega$ terminal unit, whereas the cis-trans sequence may be formed from the long cis-1,4polyisoprene. The signal at $40.0 \mathrm{ppm}$ in the ${ }^{13} \mathrm{C}-\mathrm{NMR}$ spectra of TSS $8^{\circledR}$ and SMR20 provides conclusive evidence that cis-trans isomerization occurs in the cases of 
$\mathrm{TSS}^{\circledR}$ and SMR20. These finding were consistent with those from the ${ }^{1} \mathrm{H}-\mathrm{NMR}$ spectra.

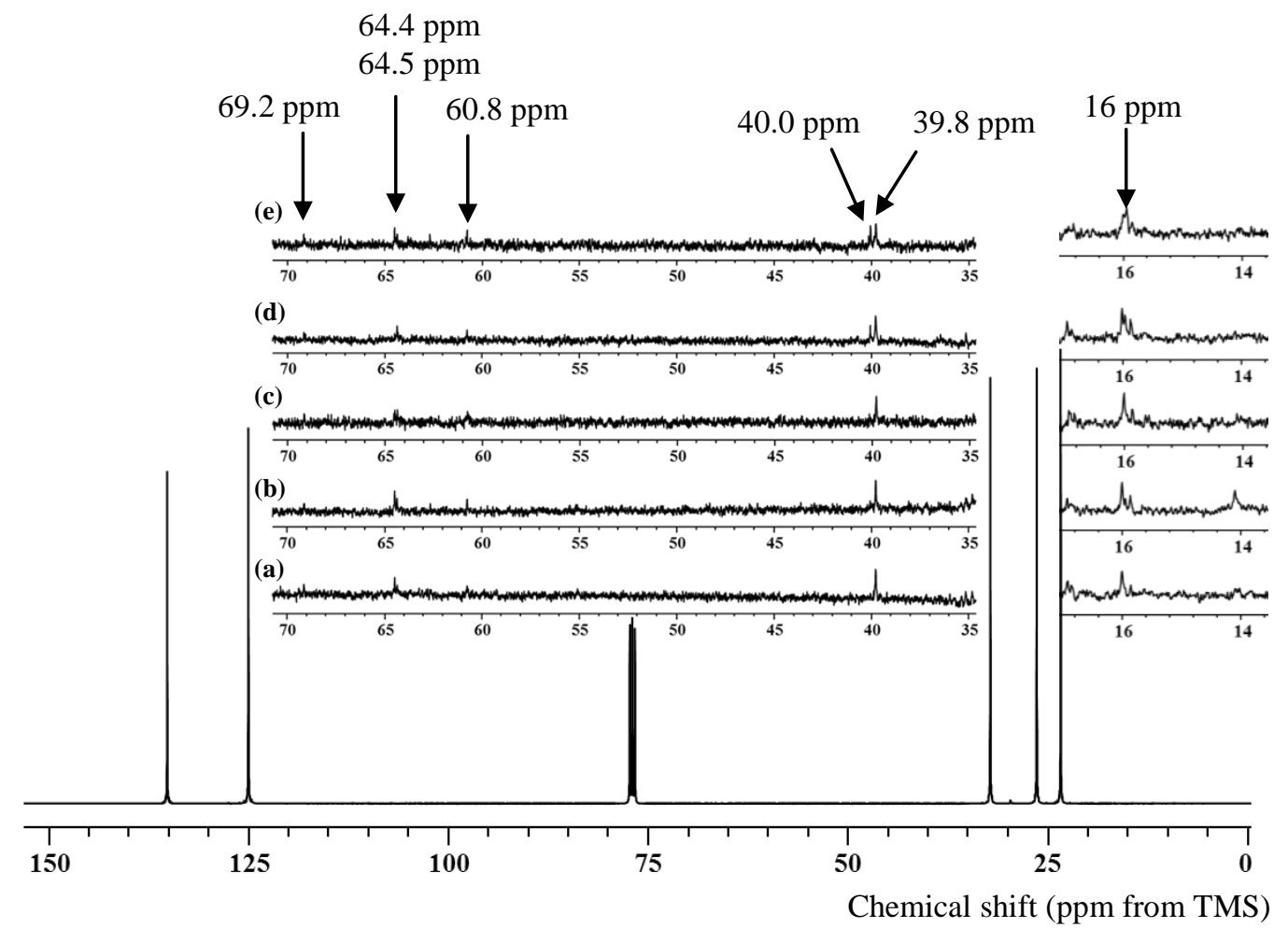

Fig.4. ${ }^{13}$ C-NMR spectra for (a) PC-AE, (b) RSS3-AE, (c) STR5L-AE, (d) TSS8 ${ }^{\circledR}$-AE and (e) SMR20-AE

In the ${ }^{13} \mathrm{C}-\mathrm{NMR}$ spectra of these samples, several small signals appeared at $60.8,64.4$, 64.5, and $69.2 \mathrm{ppm}$. As reported in the literature, the signals at 60.8 and $64.5 \mathrm{ppm}$ were assigned to $\mathrm{C} 2(-\mathrm{C}-)$ and $\mathrm{C} 3(-\mathrm{CH})$ of the cis epoxy group [14]. On the other hand, the signal at $64.4 \mathrm{ppm}$ has previously been assigned to $-\mathrm{CH}_{2} \mathrm{OP}$ in a mono- or di-phosphate group or $-\mathrm{CH}_{2} \mathrm{OCO}$ of the glyceride structure in phospholipids at the $\alpha$ terminal [15]. These four small signals in ${ }^{13} \mathrm{C}-\mathrm{NMR}$ spectrum seem to be difficult to assign correctly because of small differene in chemical shift. Therefore, it is necessary to perform DEPT measurements with various pulse sequences to determine the substitutents for each carbon atom. Fig. 5 shows the DEPT spectra for STR5L-AE as an example. The signal at $64.4 \mathrm{ppm}$ appeared downward in DEPT135, upward in DEPT45, and was null in DEPT90; hence, the signal was assigned to the methylene 
group of a secondary carbon $\left(-\mathrm{CH}_{2}\right)$. In contrast, the signal at $64.5 \mathrm{ppm}$ showed upward in the DEPT45, DEPT90, and DEPT135 spectra, and was assigned to the methine group of a tertiary carbon $(-\mathrm{CH})$. Therefore, the signal at $64.5 \mathrm{ppm}$ was due to $\mathrm{C} 3$ of an epoxy group, while the signal 64.4 ppm was from a $-\mathrm{CH}_{2} \mathrm{OP}$ or $-\mathrm{CH}_{2} \mathrm{OCO}$ group. The other signal at $60.8 \mathrm{ppm}$ was attributed to a quaternary carbon because it appeared null in the DEPT45, DEPT90, and DEPT135 spectra. The remaining signal at 69.2 ppm was assigned to a secondary carbon because it shifted upward in DEPT45, null in DEPT90, and downward in DEPT135; this signal may arise from the another methylene carbon linking to the phosphate group in the glyceride structure and not a tertiary alcohol as reported in the literature [16].
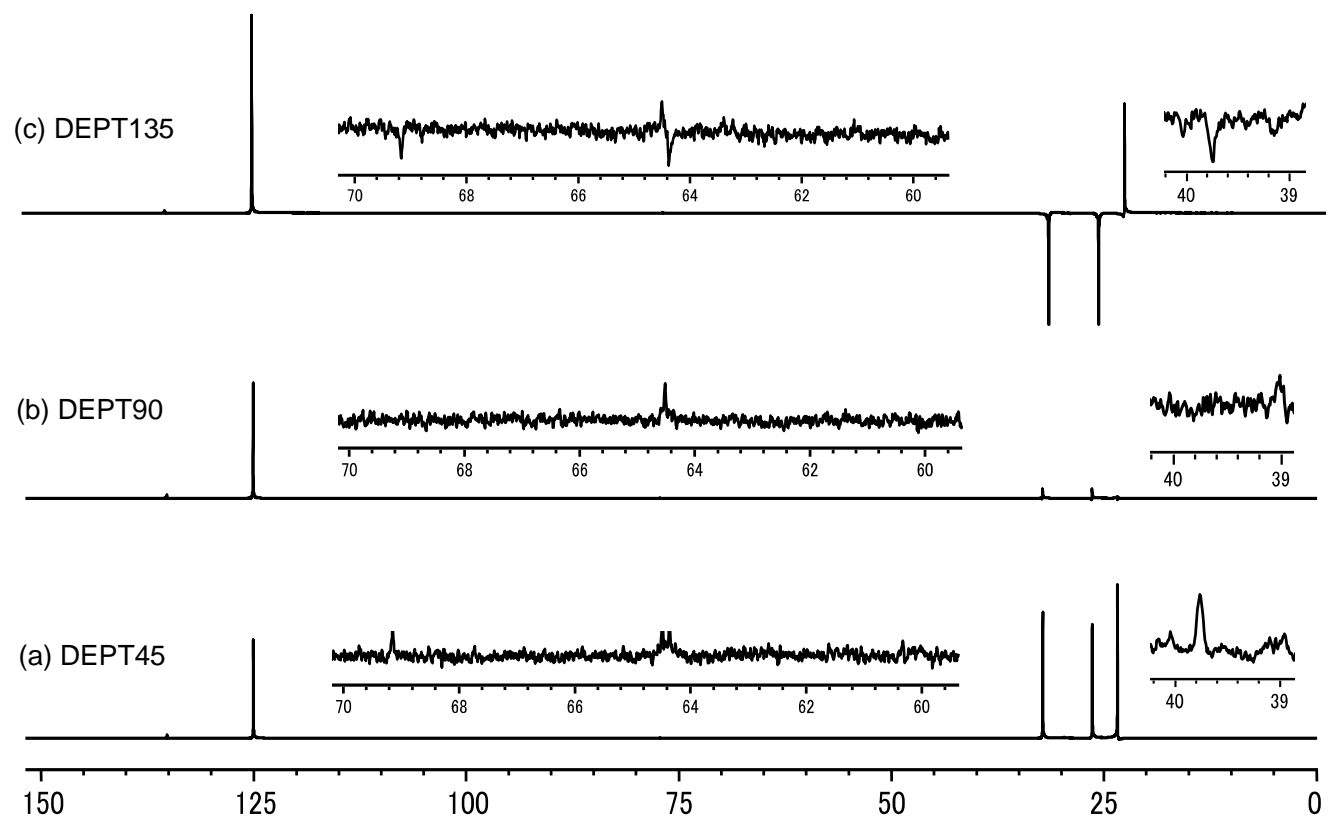

Fig.5. ${ }^{13}$ C-NMR spectra with pulse sequences of DEPT for STR5L-AE:

(a) DEPT45, (b) DEPT90, and (c) DEPT135

From the above assignments, the epoxy groups and trans-1,4-isoprene units from cistrans isomerization exist on the rubber chain of commercial NR, suggesting that epoxidation and cis-trans isomerization occur in commercial NR. Because previous works have reported that these two reactions occur during degradation of NR [17], it 
is necessary to investigate the factors that induce degradation in commercial rubbers. It is noteworthy that isomerization was found in $\operatorname{TSS}^{\circledR}{ }^{\circledR}$ and SMR20 but not in PC, RSS3, and STR5L. The main difference in preparing these samples is the temperature of the drying process (i.e. TSS $8^{\circledR}$, STR5L, and SMR20 were dried between $100^{\circ} \mathrm{C}$ and $130^{\circ} \mathrm{C}$, while PC and RSS3 were prepared at lower temperatures of $37^{\circ} \mathrm{C}$ and $70^{\circ} \mathrm{C}$, respectively). These results imply that a high temperature may be the key factor promoting the degradation of commercial rubbers.

$$
\mathrm{R}^{\cdot}+\mathrm{O}_{2} \longrightarrow \mathrm{RO}_{2} \cdot
$$
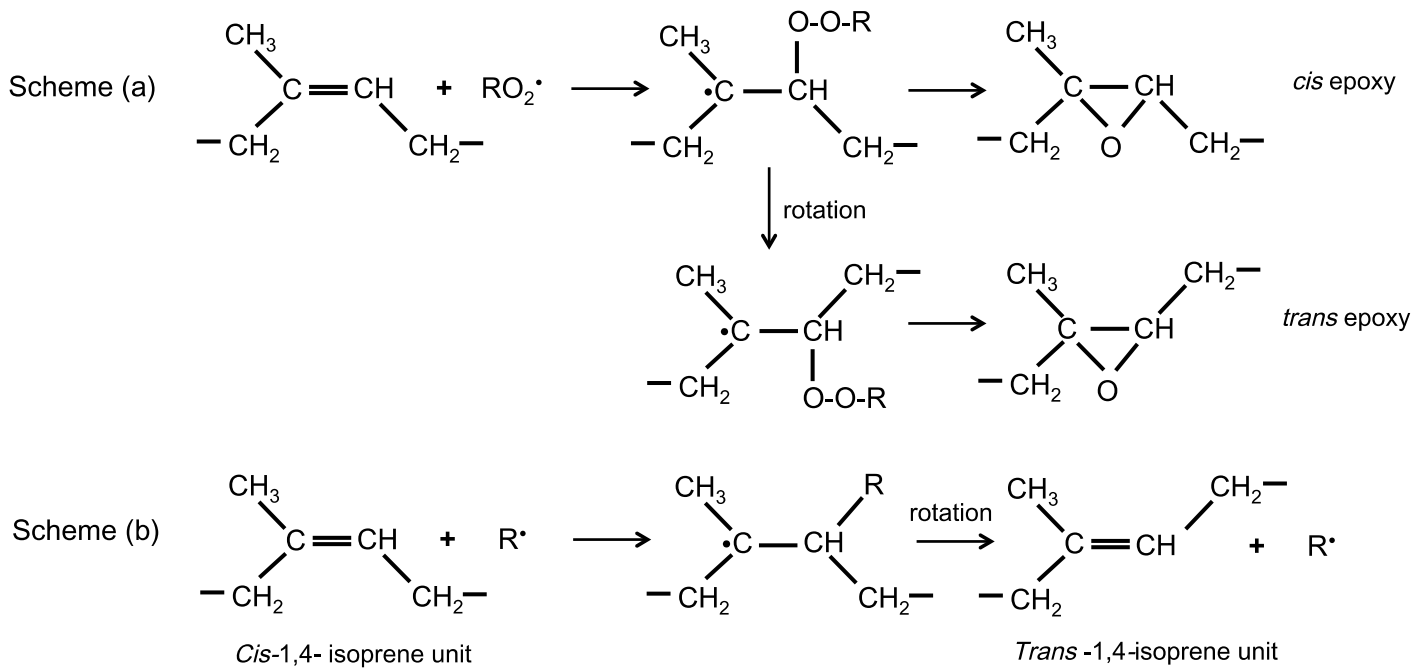

Fig.6. Schematic representation of oxidative degradation in commercial NR

In the present work, the formation of the epoxy group suggests commercial rubbers undergo oxidative degradation. Fig. 6 shows a schematic representation of the oxidative mechanism in commercial NR, which follows a radical route as reported in the literature [18]. Under high-temperature processing, radicals may be generated from the oxidation or degradation of lipids and subsequently incorporate oxygen in the air to form a peroxy radical species $\mathrm{RO}_{2}{ }^{\circ}[19]$. The peroxy radical, in turn, attacks the double bond on the rubber chain to produce a macro-radical, which then generates the epoxy group as shown in scheme (a). In the previous work, oxidative degradation of NR was reported to produce more cis than trans epoxy groups, but the trans epoxy 
group was more favorable under a high temperature [18]. However, trans epoxy group was not detected on the rubbers in the current work. On the other hand, cistrans isomerization is detected only in $\operatorname{TSS}^{\circledR}{ }^{\circledR}$ and SMR20. As shown in scheme (b), the isomerization mechanism likely involves a radial species attacking the double bond of the cis-1,4-isoprene unit followed by the rotation of the macro-radical to produce trans-1,4-isoprene unit. Under the high temperature condition, the mobility of the polymer chain favors rotation, resulting in cis-trans isomerization.

The existence of the epoxy and trans-1,4-isoprene units from isomerization are evidence of auto-oxidative degradation in commercial rubbers. To evaluate the extent of degradation (i.e., epoxidation and isomerization), the intensities of the epoxy group and trans-1,4-isoprene units were determined. The epoxy content $\left(\chi_{2.63 \mathrm{ppm}}\right)$ and trans content $\left(\chi_{1.64-1.67 \mathrm{ppm}}\right)$, were calculated based on the intensity ratio of the signal at 2.63 ppm for the epoxy group and 1.64-1.67 ppm for the trans-1,4-isoprene units, respectively, to the signal at $1.77 \mathrm{ppm}$. The equations are expressed as follows:

$$
\begin{aligned}
& \chi_{2.63 \mathrm{ppm}}(\%)=\frac{\mathrm{I}_{2.63 \mathrm{ppm}}}{\mathrm{I}_{1.77 \mathrm{ppm}} / 3} \times 100 \\
& \chi_{1.64-1.67 \mathrm{ppm}}(\%)=\frac{I_{1.64-1.67 \mathrm{ppm}}}{I_{1.77 \mathrm{ppm}}} \times 100
\end{aligned}
$$

where $I$ is the signal intensity. The subscripts represent the relevant chemical shift. Table 1 shows the values of the epoxy and the trans-1,4-isoprene units contents. The epoxy content and trans-1,4-isoprene units content were very similar. The epoxidation level of SMR20 is the highest, indicating that oxidative degradation may occur in low grades rubbers when the natural rubber is processed at a high drying temperature. 
Table 1. Epoxy content and trans content of commercial rubbers

\begin{tabular}{lll}
\hline \multirow{2}{*}{ Sample } & \multicolumn{2}{c}{ Epoxy content and trans content $(\%)$} \\
\cline { 2 - 3 } & $\chi_{2.63 \mathrm{ppm}}$ & $\chi_{1.64-1.67 \mathrm{ppm}}$ \\
\hline PC-AE & 0.015 & 0 \\
\hline STR5L-AE & 0.045 & 0.045 \\
\hline RSS3-AE & 0.048 & 0.046 \\
\hline TSS8 ${ }^{\circledR}-\mathrm{AE}$ & 0.036 & 0.037 \\
\hline SMR20-AE & 0.075 & 0.084 \\
\hline
\end{tabular}

On the other hand, the degree of cis-trans isomerization in commercial NR could be estimated by the intensity of the signals at $40.0 \mathrm{ppm}\left(\chi_{40.0 \mathrm{ppm}}\right)$ to the methyl carbon signal of the cis-1,4-isoprene unit at $23.4 \mathrm{ppm}$ as follows:

$$
\chi_{40.0 \mathrm{ppm}}(\%)=\frac{I_{40.0 \mathrm{ppm}}}{I_{23.4 \mathrm{ppm}}} \times 100
$$

where $I$ is the intensity of the signal and the subscripts represent the relevant chemical shift. Table 2 lists the estimated values for the intensity ratio of the signal at $40.0 \mathrm{ppm}$. As shown in the table, TSS $8^{\circledR}$ had lower level of cis-trans isomerization than SMR20 and cis-trans isomerization was not detected in RSS3. In previous work, cis-trans isomerization was attributed to heating in a smokehouse and the drying tunnels. Fuel combustion generates combustible gases such as $\mathrm{NO}_{2}$ and $\mathrm{SO}_{2}$, which promote cistrans isomerization in NR [7]. However, in the present work, cis-trans isomerization was not detected for RSS3, suggesting that cis-trans isomerization may be due to the processing temperature and not to combustible gases. 
Table 2. Intensity ratio of the signals at $40.0 \mathrm{ppm}$ to the signal at $23.4 \mathrm{ppm}$

\begin{tabular}{ll}
\hline Samples & $\chi_{40.0 \mathrm{ppm}}(\%)$ \\
\hline PC-AE & 0 \\
\hline STR5L-AE & 0 \\
\hline RSS3-AE & 0 \\
\hline TSS8 ${ }^{\circledR}-\mathrm{AE}$ & 0.042 \\
\hline SMR20-AE & 0.163 \\
\hline
\end{tabular}

If the epoxy group and the trans-1,4-isoprene units are due to degradation of these commercial rubbers, the distribution of these groups should to be inversely proportional to the molecular weight. Fig. 7 plots the trans-1,4-isoprene units content and epoxy group content versus the molecular weight of commercial rubbers. Both the trans-1,4-isoprene units content and epoxy groups content were inversely dependent on the molecular weight. The lower molecular weight, the higher the epoxy group content and the trans-1,4-isoprene units content. This may be explained to be due to the trans-1,4-isoprene unit and epoxy group are formed by oxidative degradation of NR during processing, since the low molecular weight fraction is able to be produced by chain scission of the rubber. Therefore, the existence of the epoxy group and the trans-1,4-isoprene unit from cis-trans isomerization are evidences of NR degradation. 


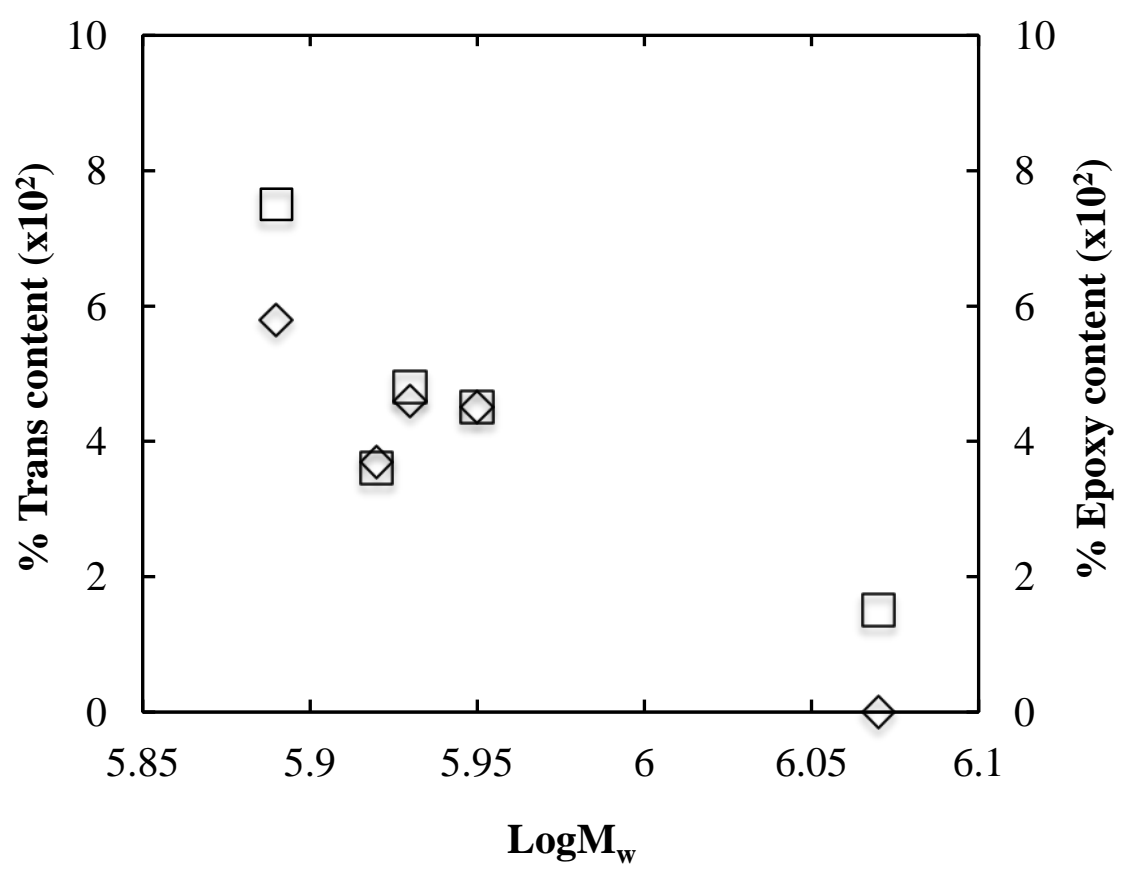

Fig. 7. Plots of the trans content $(\diamond)$ and the epoxy content $(\square)$ versus the average molecular weight of commercial rubbers

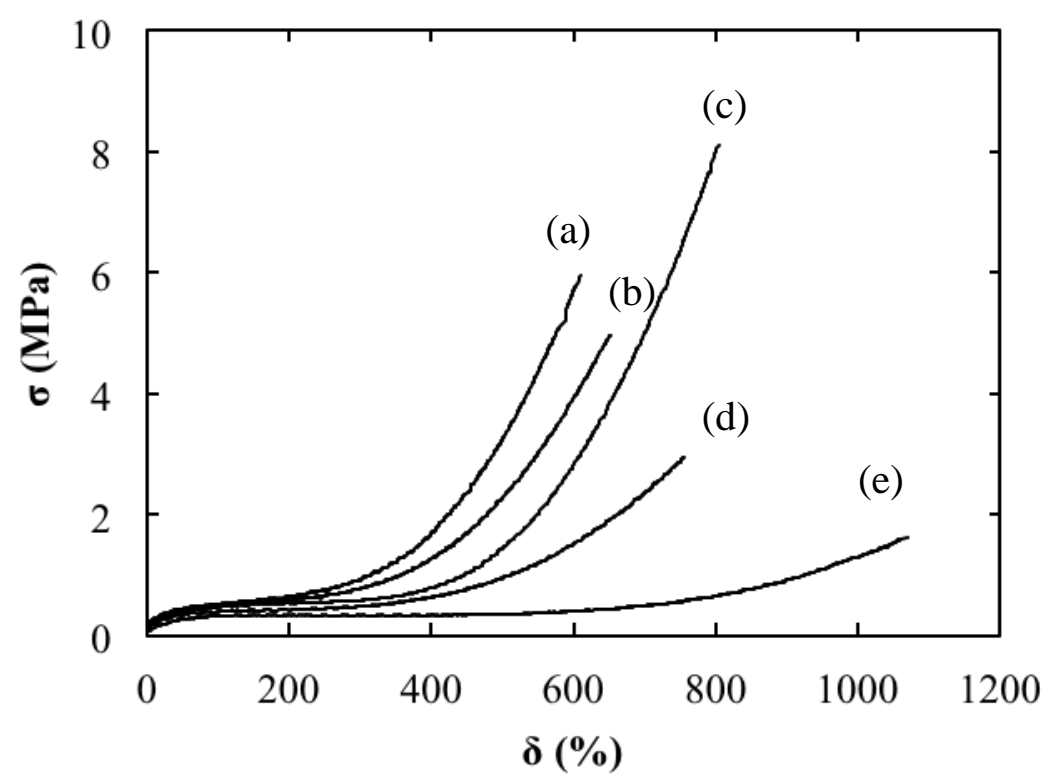

Fig.8. Stress-strain curves for (a) STR5L-AE, (b) RSS3-AE, (c) PC-AE (d) TSS $8^{\circledR}-\mathrm{AE}$ and (e) SMR20-AE

Fig. 8 shows the stress-strain curves for STR5L, RSS3, PC, TSS8 ${ }^{\circledR}$, and SMR20 after acetone extraction, where $\sigma$ and $\gamma$ represent stress and strain, respectively. The stress versus strain for PC, STR5L, RSS3, and TSS $8{ }^{\circledR}$ increased significantly at a strain of 
$300 \%$ while the stress of SMR20 increased slightly at a strain of $800 \%$. The abrupt increase in stress in a small strain region is attributed to the strain-induced crystallization of the rubbers [20]. The literature reports that the strain-induced crystallization of NR is governed by the presence of non-rubber components (i.e. proteins and phospholipids) and the naturally occurring network. Table 3 shows fatty acid content, nitrogen content and gel content of the rubbers. The highest stress for STR5L, RSS3 and $\operatorname{TSS}^{\circledR}$ at strain of $300 \%$ was ascribed to the high amount of nonrubber components, e.g. high linked fatty acid content or nitrogen content $[21,22]$. Both PC and SMR20 contained similar amount of non-rubber components, however, the stress increased abruptly during straining in PC sample, while it slightly increased in SMR20 during increasing of strain until 800\%. This phenomenon of stress-strain behavior in SMR20 suggests the flow of the rubber upon straining [22]. Since the fatty acid content of SMR20 was similar to that of PC, the flow of the rubber during straining of SMR20 sample may be explained by the absence of a naturally occurring network. This assumption was supported by the fact that the SMR20 film contains very little gel, i.e. about $6 \%$, compared to $15.1 \%$ for PC (cf Table 3).

Table 3. Nitrogen content, fatty acid ester content and gel content of the rubber films after acetone extraction

\begin{tabular}{llll}
\hline Samples & $\% \mathrm{~N}$ & $\begin{array}{l}\text { Fatty acid ester } \\
(\mathrm{mmmol} / \mathrm{kg} \text {-rubber })\end{array}$ & Gel content $\%$ \\
\hline PC-AE & 0.276 & 8.4 & 15.1 \\
STR5L-AE & 0.408 & 13.5 & 11.1 \\
RSS3-AE & 0.345 & 8.5 & 5.2 \\
TSS8 ${ }^{\circledR}$-AE & 0.435 & 7.6 & 7.0 \\
SMR20-AE & 0.176 & 9.9 & 6.0 \\
\hline
\end{tabular}




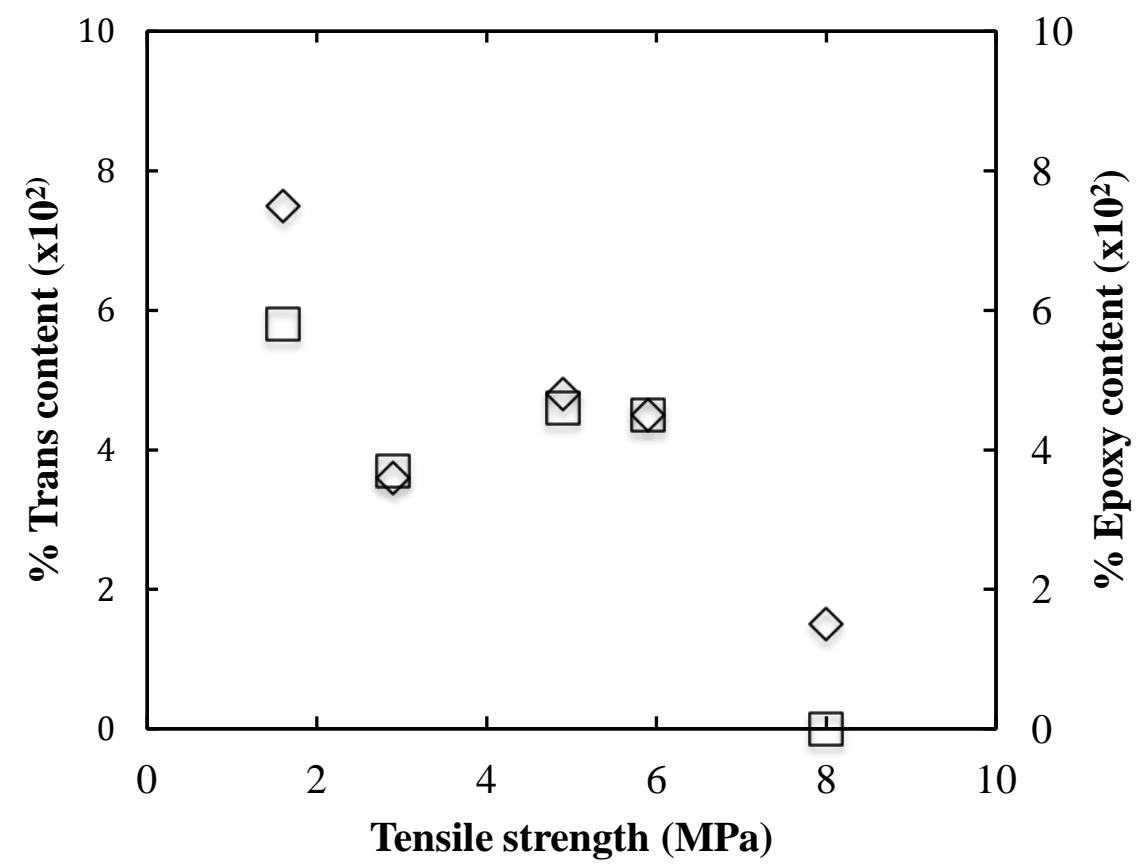

Fig. 9. Plots of the trans content $(\square)$ and the epoxy content $(\diamond)$ versus tensile strength of commercial rubbers

The stress at the break point of the rubbers was determined for each sample during extension. PC had the highest stress value of $8.0 \mathrm{MPa}$, whereas those of STR5L, RSS3, TSS $8^{\circledR}$, and SMR20 were 5.9, 4.9, 2.9, 2.7, and 1.6 MPa, respectively. The high stress at break of PC and STR5L may correspond to the high gel content, those were $15.1 \%$ and $11.1 \%$, respectively. However, it seems to be difficult to explain the difference stress at break of RSS3, TSS $8^{\circledR}$ and SMR20 in spite of similar amount of gel. By taking into account the degradation of the rubbers during processing, we may examine the effect of the damage of the rubbers on its mechanical properties. Fig. 9 plots the trans-1,4-isoprene units content and epoxy group content versus stress at the break of commercial rubbers. As the content of the abnormal groups increased, the stress at the break of the rubbers decreased. The lower the stress at the break of the rubbers having the higher epoxy and trans-1,4-isoprene unit contents may be explained to be due to the lower crystallizability. It is reasonable to hypothesize that 
the crystallizability of NR is mainly due to the characteristic of the long sequence of the cis-1,4-isoprene units of NR [23]. The existence of the epoxy group or trans-1,4isoprene on the main chain of the rubber molecules should shorten the long cis-1,4isoprene sequence and consequently, reduce the tensile strength of the rubbers. Therefore, oxidative degradation is the main factor affecting the green strength of natural rubber.

\section{Conclusions}

Two abnormal groups, the trans-1,4-isoprene unit from cis-trans isomerization and the epoxy group, were present in the main chain of the rubber molecule as evidence from the structure characterization of various commercial NR through NMR spectroscopy. The increases in the trans-1,4-isoprene unit content and epoxy group content as the molecular weight decreased suggest that the low molecular weight fractions were the degradation products of NR. Consequently, the mechanical properties were inversely proportional to the amount of abnormal groups in commercial rubbers. Although epoxidation occurs in PC, RSS3, STR5L, TSS8 ${ }^{\circledR}$ and SMR20, the cis-trans isomerization was only observed in TSS $8^{\circledR}$ and SMR20. The cis-trans isomerization in $\mathrm{TSS}^{\circledR}$ and SMR20 was related to the high drying temperature used to prepare commercial rubbers (i.e., more than $100^{\circ} \mathrm{C}$ ). This finding indicates that the drying temperature is an important factor inducing the degradation and consequently, the mechanical properties of commercial NR.

\section{Acknowledgements}

This work was supported in part by a Grant-in-Aid (26620176) for Challenging Exploratory Research and Grant-in-Aid (25288098) for Scientific Research (B) from Japan Society for the Promotion of Science and JST-JICA SATREPS. 


\section{References}

[1] Burfied D, Chew L, Gan S. Distribution of abnormal groups in natural rubber, Polymer 1976; 17(8):713-716.

[2] Eng A, Tangpakdee J, Kawahara S, Tanaka Y. Distribution and origin of abnormal group in natural rubber. J Rubb Res 1997;12(1):11-20.

[3] Cunneen J. Cis-trans isomerization in natural polyisoprene. Proceeding of the international rubber conference, Washington 1959;514-520.

[4] Tangpakdee J, Tanaka Y. Branching in natural rubber, J Rubb Res 1997;1(1):1421.

[5] Amnuaypornsri S, Tarachiwin L, Tangpakdee J. Character of long-chain branching in highly purified natural rubber. J Appl Polym Sci 2010; 115(6): 36453650.

[6] Farley P. Geometrical isomerization of polyisoprenes. Part 2. Factors determning the trans alkene content of natural rubber. J Nat Rubb Res 1991;6(4):223-229.

[7] Farley P. Geometrical isomerization of polyisoprenes. Part 1. Occurrence and estimationg of trans alkene functionality in natural rubber. $J$ Nat Rubb Res 1991;6(4):215-222.

[8] Eng A, Kawahara S, Tanaka Y. Trans isoprene units in natural rubber. Rubb Chem Technol 1993; 67:159-168.

[9] Chaikumpollert O, Sae-heng K, Wakisaka O, Mase A, Yamamoto Y, Kawahara S. Low temperature degradation and characterization of natural rubber. Polym Degrad Stab 2011;96:1989-1995.

[10] Eng A, Kodama S, Tangpakdee J, Kawahara S, Tanaka Y. Epoxide group in natural rubber. II. ${ }^{13} \mathrm{C}$ study of undegraded natural rubber. J Rubb Res 1998;1(4):199208. 
[11] Processing of natural rubber. John C, Pete M 2003;1-129.

[12] Rubber Research Institute of Malaysia SMR Bulletin 1973; No 17.

[13] Sakdapipanich J. Current study on structural characterization and unique film formation of Hevea Brasiliensis natural rubber latex. Adv Mat Res 2014; 844:498501.

[14] Sato K, Klinklai W, Kawahara S. Characterization of epoxidized natural rubber by 2D-NMR spectroscopy. Polymer 2007;48:750-757.

[15] Tanaka Y. Structural characterization of natural polyisoprenes: solve the mystery of natural rubber. Rubb Chem Technol 2001; 67:355-275.

[16] Yunyongwattanakorn J, Sakdapipanich J. Recent advances in structural characterization of natural rubber. Rubb Chem Technol 2009;82:283-314.

[17] Tangpakdee J, Kowitteerawut T, Kawahara S, Tanaka Y. Depolymerization of highly purified natural rubber. I. Metal-catalyzed oxidation of deproteinzed natural rubber. J Rubb Res 2001;4(1):1-10.

[18] Eng A, Kodama S, Tangpakdee J, Kawahara S, Tanaka Y. Epoxide group in natural rubber. I. ${ }^{13} \mathrm{C}$ study of oxidative degraded rubbers. J Rubb Res 1998;1(2):6776.

[19] Sakdapipanich J, Rojruthai P. Molecular structure of natural rubber and its characteristic based on recent evidence. In: Sammour, R.H. (Ed.), BiotechnologyMolecular Studies and Novel Applications for Improved Quality of Human Life. Biochemistry, Genetics and Molecular Biology. InTech. 2012: 159-172. [doi:10.5772/2519]

[20] Toki S, Benjamin S, Amnuaypornsri S, Sakdapipanich J. New insight into the relationship between network structure and strain-induced crystallization in unvulcanized and vulcanized natural rubber by synchrotron X-ray diffraction. Polymer 
2009; 50:2142-2148.

[21] Amnuaypornsri S, Kawahara S, Toki S, Hsiao B, Hikosaka M, Sakdapipanich

J, Tanaka Y. Strain-induced crystallization of un-vulcanized natural rubber measured by synchrotron X-ray diffraction. Kaut Gummi Kunst 2012;6: 46-50.

[22] Amnuaypornsri S, Sakdapipanich J, Toki S, Hsiao B, Ichikawa N, Tanaka Y. Strain-induced crystallization of natural rubber: effect of proteins and phospholipids. Rubb Chem Technol 2008; 81(5):753-766.

[23] Burfied D, Tanaka Y. Cold crystallization of natural rubber and its synthetic analogues: The influence of chain microstructure. Polymer 1987;28: 907-910. 
Fig.1. Preparation of a rubber film by the solution casting method

Fig. 2. ${ }^{1}$ H-NMR spectra for (a) PC-AE, (b) RSS3-AE, (c) STR5L-AE, (d) TSS $8{ }^{\circledR}$-AE and (e) SMR20-AE

Fig.3. Expanded ${ }^{1}$ H-NMR spectra for sol fraction of (a) PC-TE, (b) RSS3-TE, (c) STR5L-TE, (d) TSS $8{ }^{\circledR}$-TE and (e) SMR20-TE

Fig.4. ${ }^{13}$ C-NMR spectra for (a) PC-AE, (b) RSS3-AE, (c) STR5L-AE, (d) TSS8 ${ }^{\circledR}$-AE and (e) SMR20-AE

Fig.5. ${ }^{13}$ C-NMR spectra with pulse sequences of DEPT for STR5L-AE: (a) DEPT45, (b) DEPT90, and (c) DEPT135

Fig.6. Schematic representation of oxidative degradation in commercial NR

Fig.7. Plots of the trans content $(\diamond)$ and the epoxy content $(\square)$ versus the average molecular weight of commercial rubbers

Fig.8. Stress-strain curves for (a) STR5L-AE, (b) RSS3-AE, (c) PC-AE, (d) TSS8 ${ }^{\circledR}$ $\mathrm{AE}$ and (e) SMR20-AE

Fig.9. Plots of the trans content $(\square)$ and the epoxy content $(\diamond)$ versus tensile strength of commercial rubbers 